\title{
A scenario analysis of Beijing's private traffic patterns
}

\author{
Jingru Liu*, Rusong Wang, Jianxin Yang \\ Research Center for Eco-Environmental Sciences, Chinese Academy of Sciences, 18 Haidian District, Shuangqing Road, Beijing 100085, China
}

Accepted 25 May 2006

Available online 14 July 2006

\begin{abstract}
Sustainable development is a basic state policy of China. Changing the unsustainable production and consumption patterns plays an important role in implementing this policy. In this paper, taking private traffic pattern of Beijing as an example, we compare the life-cycle environmental impacts of different scenarios. Assumptions which concern the role of both consumers and producers are taken in scenarios' development. Scenario results show that combing sustainable consumption and production patterns is essential for future. This paper gives some policy implications about the role of government in promoting sustainable private traffic patterns in Beijing.
\end{abstract}

(C) 2006 Elsevier Ltd. All rights reserved.

Keywords: Sustainable production; Sustainable consumption; Private traffic pattern; Life-cycle assessment (LCA)

\section{Introduction}

In the past, producers were regarded as the core of sustainable development. After Rio Conference in 1992, consumers were promoted to the same level of importance. In 2002, at the summit in Johannesburg, research on consumers was much more emphasized [1]. As an important part of product's life cycle, consumers have an important influence on the whole product chain. The integration of sustainable production and consumption is the prerequisite of sustainable development [2,3].

Sustainable development is a basic state policy of China. Changing the unsustainable production and consumption patterns plays an important role in implementing this policy. Social responses to environmental problems have focused largely on the production side of economic activities: innovative technologies for material mining, energy supplying and manufacturing. Facts show that environmental gains achieved by such producer-orientated policies are offset by trends on the consumer side - population growth, higher standard of living and people's desires to consume products and services [4-6]. As a country like China with a large population and scarce resources, more attention should be put on consumers if sustainable development is to be realized.

\footnotetext{
* Corresponding author. Tel.: +86 10 62849110; fax: +86 1062943807 .

E-mail address: liujingru@vip.sina.com (J. Liu).
}

Motorization of private traffic is a clear trend in China, especially in big cities. On the one hand, motorization promotes life quality, brings mobility and comfort, and provides more choices for people's employment and residence; on the other, it also leads to environmental problems, an especially serious pressure with decreasing air quality. In this paper, taking Beijing as an example, we first introduce the motorization of private traffic in Beijing and its social and economic backgrounds. Then we compare the life-cycle environmental impacts of low-motorization, middle-motorization and high-motorization development scenarios in 2020 with the base year 2000. Assumptions which concern the consumers' choices and technology advancement are taken in scenarios development. This paper emphasizes the important effect of the integration of production and consumption. At last, this paper gave some suggestions on the role of government to promote sustainable private traffic in Beijing.

\section{Motorization of private traffic in Beijing and its environmental impacts}

\subsection{Motorization and the changes of private traffic mode in Beijing}

Beijing is currently experiencing one of the highest annual motorization growth rates in the world $[7,8]$. Private ownership 


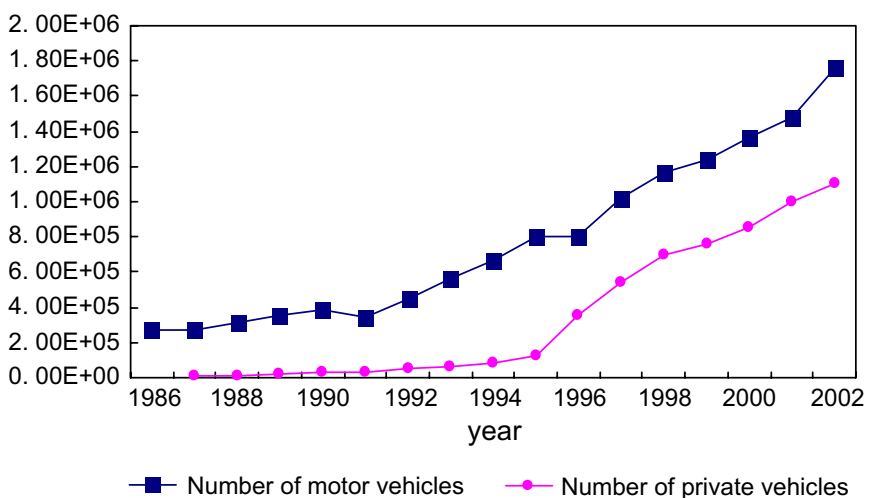

Fig. 1. Number of motor vehicles and private vehicles in Beijing.

of automobiles was strictly restricted by the state; the majority of passenger vehicles were traditionally owned by government and state-owned enterprises. Along with the adoption of an open-door policy and the shift to a more market-oriented economies, the government has begun relaxing restrictions on private vehicle ownership; as a result, the number of privately owned vehicles has grown substantially in a relatively short period of time [9]. Fig. 1 shows that at the end of 2000, the total vehicle stock in Beijing was about 1.36 million; more than five times that of what is was in 1986 and with an annual growth rate of $13 \%$ [10]. The rapidly increasing trend of private cars came after mid-1990s. Private purchase of automobiles increased at an annual rate of $44 \%$ between 1986 and 2000. Private vehicle population in Beijing between 1986 and 2000 has grown to about 120 times. In 2003, there are 0.8 million private cars in Beijing, a motorization rate of 11 vehicles per 1000 population [11]. Private purchase of automobiles accounts for more than $90 \%$ of new fleet in Beijing automobile market in 2003.

China has long been known for its widespread use of bicycles in urban transport. This situation has changed to a considerable degree with the increasing use of automobiles for work and leisure activities. Two surveys, in 1986 and 2000, on private traffic mode have been carried out in Beijing by the government. These results, shown in Fig. 2 [12], reflect the motorization trends of private traffic mode. Bicycle took up $58 \%$ of passenger traffic demand in 1986. This proportion declined to $38 \%$ in 2000; the share of public buses as a whole declined from $32 \%$ in 1986 to $27 \%$ in 2000 , while the total number of passenger buses is estimated to have increased from 6000 to 15,000 during this period [10]; and the share of private cars in total passenger traffic volume increased from 5\% in 1986 to $23 \%$ in 2000. It is assumed that the share of private motorized travel demand will increase in the future due to the government's policy of encouraging private car.

\subsection{Environmental impacts of motorization in Beijing}

The rapidly increasing vehicle fleet, combined with low emission standards, poor road infrastructures, outdated technologies and unmatched monitoring systems, makes Beijing as one of the most polluted city in the world. It is reported that under actual operation conditions, the average emission rate of carbon monoxide $(\mathrm{CO})$ and hydrocarbons $(\mathrm{HC})$ of cars in Beijing is four to five times higher than those of similar cars in U.S. Compared with developed countries, the emission rate of newly produced cars in Beijing is 10 times higher [13]. This is particularly true for $\mathrm{CO}, \mathrm{HC}$, nitrogen oxides $\left(\mathrm{NO}_{x}\right)$ and a variety of potentially harmful emissions. Table 1 shows the increasing contribution of vehicle emission to total air emissions in 1995, 1998 [14] and 2000 [9] in Beijing. From 1995 to 2000 , the percentage of total vehicle emission CO increased from 76.8 to 84 and $\mathrm{NO}_{x}$ increased from 21.7 to 73 . Motor vehicles' emissions now constitute the main source of air pollution in Beijing. The growing vehicle population is one of the most urgent problems facing 2008 Beijing Olympics.

\section{Driving forces of private traffic motorization in Beijing}

Motorization of individual traffic patterns is influenced by income, urban structure, policy and habits, etc. The individual's right to unlimited, motorized, personal mobility has emerged as an important measure of progress in modern democratic societies [15]. In China, private cars are regarded as an important symbol of promotion of living condition and social status. Therefore private purchase of cars is encouraged by policy and is a target of many families. As to Beijing, its sprawling also spurs family cars buying and changing in employment patterns.

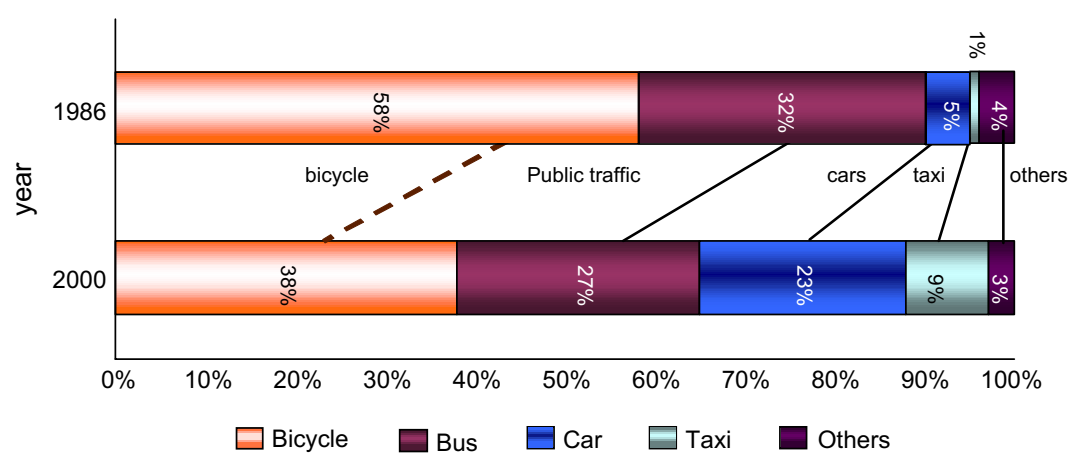

Fig. 2. Private traffic mode of Beijing between 1986 and 2000. 
Table 1

Contribution of vehicle emissions to Beijing air pollution (\%)

\begin{tabular}{lll}
\hline Year & $\mathrm{CO}$ & $\mathrm{NO}_{x}$ \\
\hline 1995 & 76.8 & 21.7 \\
1998 & 82.7 & 40.2 \\
2000 & 84 & 73 \\
\hline
\end{tabular}

\subsection{Economic development and increasing family income}

Cases from developed countries show that vehicle ownership is strongly correlated with its per capita gross domestic product (GDP) and average personal income [16]. Thus when income rises by $1 \%$, the number of motor vehicles rises by $1 \%$ and the number of automobiles increases by about $1.2 \%$ [17]. Experience shows that when per capita GDP is lower than 300 USD, urban cars are mostly business cars and when per capita GDP is higher than 3000 USD, cars become as major transport vehicles of middle class families and families with high income [18] (Table 2). Beijing is going through a similar motorization process compared to developed countries. In this process, the private car will be the first choice of individual motorized traffic after the growth of per capita GDP reaches 3000 USD.

The availability of spare income provides individuals and households the economic opportunity and practical option to purchase private cars [19]. International experience shows that a family whose $1.5-2$ years income is equal to a car's price can afford a car and is a potential buyer. In 2003, the average annual disposable income per family was 41,650 RMB yuan in Beijing. According to the statistics of Ya Yun Cun car market, the largest car market in Beijing, cars of around 100,000 RMB yuan, which is equal to 2 years' income of average family, enjoy the largest turnover. The most popular car brands and their prices in 2003 are shown in Table 3 [20].

\subsection{Urban structure and density}

Motorization of private traffic patterns and city's sprawling promotes mutual growth [17]. To decrease the pressure of population density in central city, the attraction of land price in city suburbs, and pursuit to a modern life style makes Beijing's sprawl as rapid as that of other metropolises. Fig. 3 [21] shows the rapid built area sprawling from 1975 to 2002, the built area increased from $391 \mathrm{~km}^{2}$ to $490.1 \mathrm{~km}^{2}$ during this period. Such

Table 2

Number of cars and per capita GDP in China

\begin{tabular}{lll}
\hline Owner & $\begin{array}{l}\text { Per capita } \\
\text { GDP (USD) }\end{array}$ & $\begin{array}{l}\text { Vehicles per } \\
1000 \text { people }\end{array}$ \\
\hline $\begin{array}{l}\text { As business's property, for } \\
\text { official use } \\
\begin{array}{l}\text { Beginning to buy cars, for official } \\
\quad \text { use, for taxi }\end{array}\end{array}$ & 300 & 2 \\
$\begin{array}{l}\text { Increasing, for business owners for } \\
\text { those with high income }\end{array}$ & $300-1000$ & 10 \\
$\begin{array}{l}\text { Spreading, for the middle class and above } \\
\text { Mature, developed countries }\end{array}$ & $>3000$ & $10-50$ \\
\hline
\end{tabular}

Table 3

Top five popular cars in Ya Yun Cun car market

\begin{tabular}{lcc}
\hline Brand & Price $(10,000$ RMB yuan) & Share $(\%)$ \\
\hline XiaLi (Toyata Platz) & 5 & 11.06 \\
JieDa (Shanghai Volkswagen) & 10 & 10.89 \\
AiLiShe (Citroen) & 11 & 7.06 \\
FuKang (Citroen) & 9 & 5.66 \\
QiRui (Ford Technology) & 11 & 4.88 \\
\hline
\end{tabular}

decentralization jeopardizes the feasibility of public transport, which cannot serve low-density areas effectively. This gives private car ownership a chance to develop rapidly to meet the requirement of citizen transportation. The motorization of private traffic patterns, in consequence, will further promote the sprawling of city development [22].

To decrease the population density in downtown, Beijing Municipal Government keeps encouraging development of multi-centers of the city. From 1990 to 2000, the number of small towns in the suburban area increased from 77 to 142 . This trend will continue with the implementation of Beijing's new master plan which was formulated in 2004. According to this new plan, the population scale of Beijing will be limited to 18 million in 2020, 7.5 million of which will be distributed in new towns and small towns in suburban areas (Fig. 4) [21]. Meanwhile, foreign practice will be adopted to change mixed land use into land use of functional districts, which leads to more traffic volume and long travel distances and therefore increases dependence on motorized transport.

\subsection{Government policy}

Government policy has a significant effect on the characteristics of China's motor vehicle fleet. Increase in the use of private vehicles is largely the result of government policy to promote economic development through automobile sector growth and infrastructure development [22,23]. In the mid1980s, the restriction on purchasing private cars was abolished and the production of cars was regarded as an important task of the auto industry to accomplish this goal. In 1994 and 2004, two Chinese Auto Industry Policies were launched, respectively, by the central government, both stipulate that the private car is the pillar of auto industry development, and a series of instruments were implemented to foster the domestic private car market. Beijing Municipal Government, who also regarded production and consumption of private car as an important economic pillar, has adopted similar policies. To realize the objective, Beijing Municipal Government has adopted a number of policies to stimulate the use of private vehicles, such as provision of car mortgage and deduction of relevant fees for vehicle use, lengthening the use life of passenger cars from 10 to 15 years [22] and providing officials with an allowance to buy private cars. These policies largely reflect the official desire to develop a car-based transport system.

While vital to a modern economy, there are obvious negative consequences of this rapidly growing vehicles fleet in Beijing. To fulfill the commitment for 2008 Olympics and to improve the air quality, vehicle-related emissions control has 

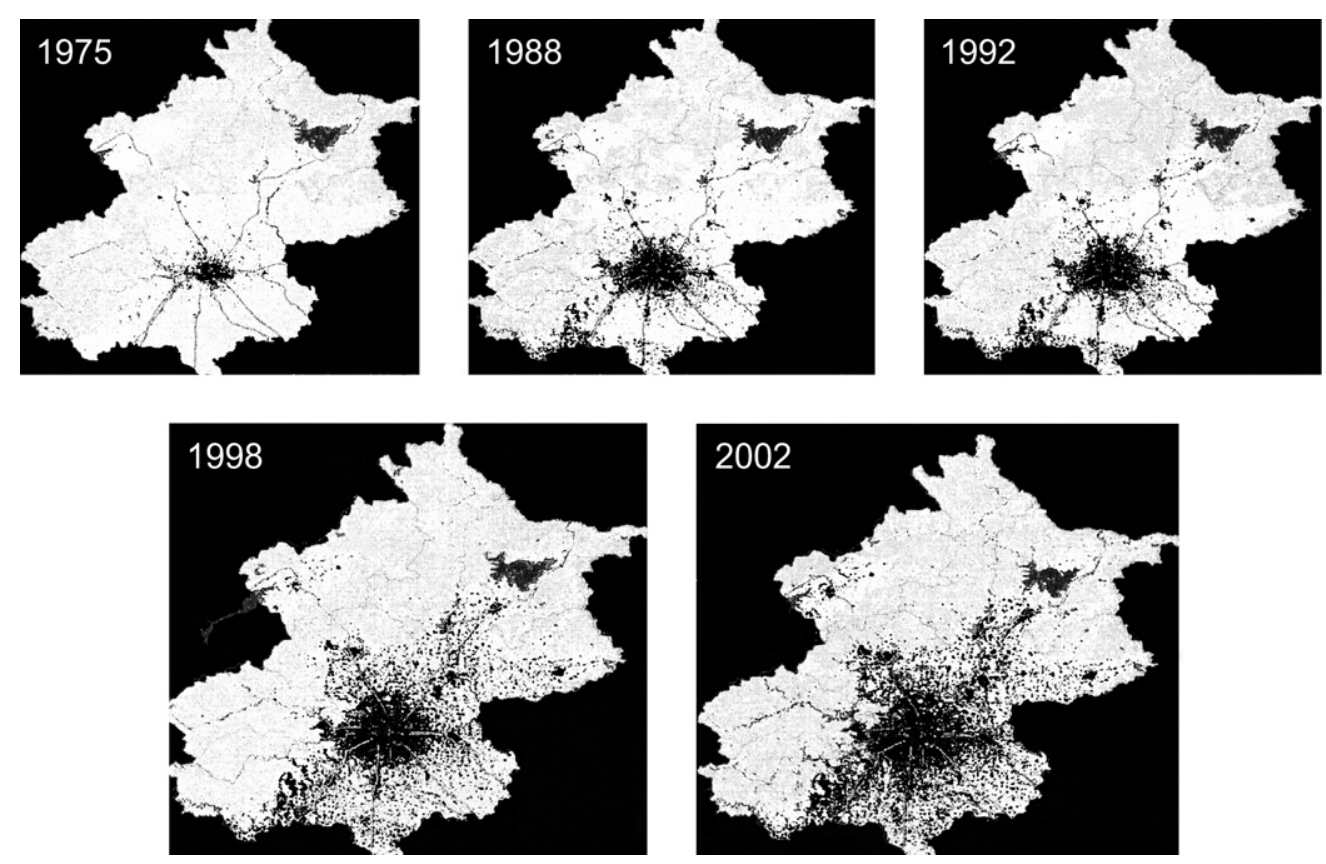

Fig. 3. Built area sprawling in Beijing (from 1975 to 2002).

become a key concern in the governmental policies. A huge amount of money has been invested in transport infrastructure development, stricter new-car-emission standards (compared to other regions of China) are in place, and fuel substitutes are used on buses and taxies. The traditional command-andcontrol policy approach makes the government use regulatory measures relatively effective in regulating industrial behaviors; however, facts show that all these efforts taken by the government did not stop the worsening of air quality. It has become clear that technical solutions alone will not be sufficient

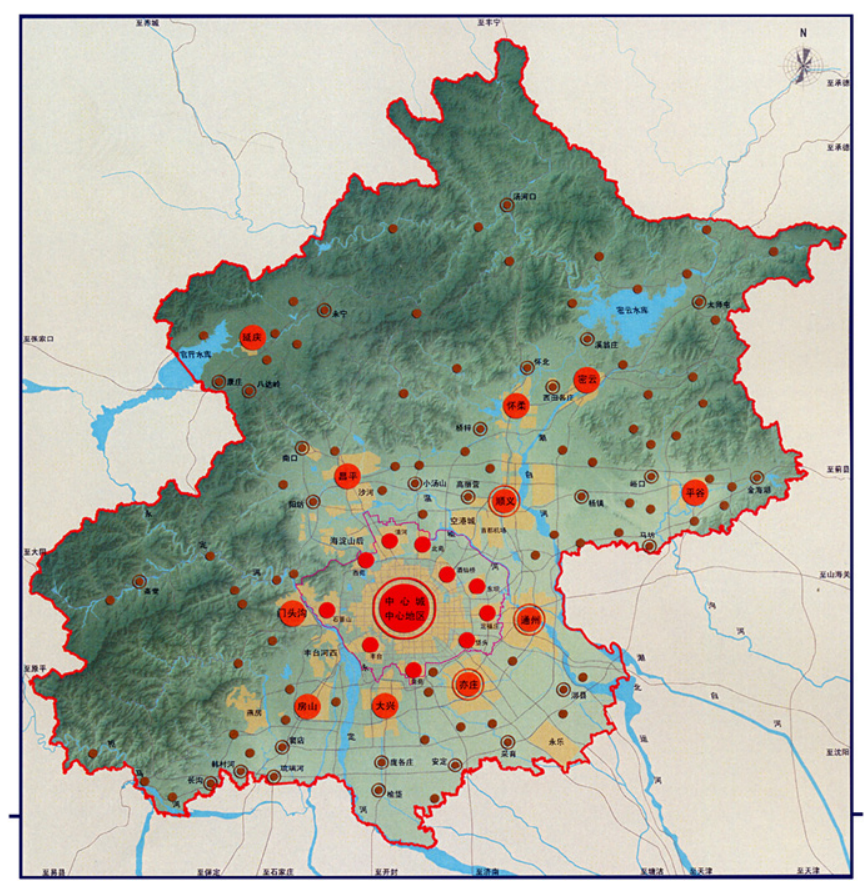

Fig. 4. Planned new towns and small towns of Beijing in 2020. to mitigate transport's negative impacts with increasing vehicle numbers, travel frequency and trip length [15].

Together with technical development, the government should also think of this issue from a consumption perspective, to take actions and instruments to encourage consumers to choose environmentally friendly traffic mode. Scenario analyses in Section 4 below show the effect of both producer and consumer in mitigation the problems of motorization process in Beijing.

\section{Scenarios of private traffic patterns in $\mathbf{2 0 2 0}$}

\subsection{Life-cycle assessment of private traffic patterns}

The environmental impacts of consumption can be decomposed into three determinants: the level of consumption, the composition of consumption and the environmental intensity of goods and services produced for consumption, including both direct and indirect effects [24]. According to this decomposition, the environmental impacts of private traffic are decided by three factors:

Traffic volume: the consumption level of private traffic demand;

Traffic mode: the composition of private traffic consumption, except walking, more than $80 \%$ of which are provided by bus, car and bicycle in Beijing (Fig. 1);

Environmental intensity of traffic mode: the life-cycle environmental impacts of each traffic mode, which includes both direct and indirect impacts.

Considering that the goal of traffic is to provide service to people, we define the functional unit as one passenger kilometer (passenger-km), which means to make people move $1 \mathrm{~km}$ 
by different traffic modes. This definition fixes the first factor (traffic volume) we defined above, and then the environmental impacts of private traffic pattern are decided by the other two factors, the traffic mode and the life-cycle environmental impacts of it.

Some key parameters and data sources of our LCA analysis are listed below:

The boundary definition of life-cycle stage in our research starts from raw material extraction to operation stage and only bus, car and bicycle are considered. Waste collection and disposal stages were not considered here because other research results show that the production and operation stages account for $90 \%$ of life-cycle environmental impacts [25].

We use $\mathrm{CO}, \mathrm{CO}_{2}$ and $\mathrm{NO}_{x}$ emissions as factors to reflect the environmental impacts of private traffic pattern. These three factors are the most interesting topics in vehicle atmospheric impacts concerns $[7-9,14]$.

The life-cycle inventory data of air emissions were calculated based on Chinese factors with the support of the European Community INCO project called "Eco-Comparability of Industrial Processes for the Production of Primary Goods" [26].

To organize the inventory data based on functional unit, we assume that the average mileage of private car in its 10-year life span is $250,000 \mathrm{~km}$ with an average occupancy rate of 1.5 persons. The mileage of bus in its 10 -year life span is $500,000 \mathrm{~km}$ with an occupancy rate of 50 persons. And the bicycle can be used for 10 years, running $7000 \mathrm{~km}$ per year with the occupancy rate of one person. These assumptions were taken from reference [13] and our interviews with drivers.

Table 4 shows the life-cycle emissions of private car, bus and bicycle to provide one functional unit service separately. We find that to provide one passenger-km's service, private car is the most environmentally intensive travel mode. The $\mathrm{CO}_{2}$ emission of private car to provide one passenger-km service is eight times compared to a bus and about 51 times to a bicycle. The $\mathrm{NO}_{x}$ emissions of private car are nearly four times of a bus and 12 times of a bicycle. And the $\mathrm{CO}$ emission of a car to provide one passenger-km service is 15.07 times over a bus, and 3060 times over a bicycle.

\subsection{Scenarios of private traffic patterns and their environmental impacts in 2020}

With the development of the economy and the improvement of life quality, the private traffic motorization trend of

Table 4

Life-cycle emissions of bus, car and bicycle to provide one functional unit service

\begin{tabular}{llll}
\hline Life-cycle emissions & $\mathrm{Car}$ & Bus & Bicycle \\
\hline $\mathrm{CO}(\mathrm{g} /$ passenger-km) & 30.6 & 2.03 & 0.01 \\
$\mathrm{CO}_{2}(\mathrm{~g} /$ passenger-km) & 70.6 & 8.38 & 1.39 \\
$\mathrm{No}_{x}$ (g/passenger-km) & 1.27 & 0.33 & 0.06 \\
\hline
\end{tabular}

Beijing has been very obvious in the last decade and will continue in the future. Based on the relationship between per capita GDP and traffic volume, it was forecasted that the private traffic demand of Beijing would reach $109.30 \times 10^{9}$ passenger-km in 2020, 2.17 times over 2000 [27]. Supposing that the private traffic volume is fixed in 2020 , the environmental impacts of private traffic will depend on the choices of consumer on how to satisfy their demands and what kind of vehicles the producers provide.

\subsubsection{Scenarios design}

Taking 2000 as the base year, in this section, three scenarios of motorization level were developed to reflect the environmental impacts of consumers' choices. The other scenarios were developed under these motorization levels separately to reflect the role of producers to mitigate the environmental impacts of consumers.

A scenario is a hypothetical sequence of logical and plausible issues; it is not an exact prediction about the future. In this paper, we take three kinds of typical modal splits from developed countries as references: American mode, French mode and Japanese mode [18], to construct scenarios of motorization level to analyze the influence trends of consumers' choices on environment.

In the high motorization scenario, we assume that Beijing will follow the way of America and the automotive industry will still be a pillar of Beijing's economic development, consumers are encouraged to buy and to use cars. The traffic modes will reach America's level in 2020, 93.24\% of private car, $3.19 \%$ of bus and $0.43 \%$ of bicycle. In the middle level scenario, we assume that Beijing government, like France, will adopt a series of measures to restrict use of private cars. Cars will increase their shares of total passenger travel from $23 \%$ in 2000 to $56 \%$ in 2020 and buses increase from $27 \%$ to $37 \%$. In the low motorization scenario, we assume that Beijing will develop a sound public traffic system as Japan has done which provides $70.6 \%$ of passenger traffic volume. The other $24.6 \%$ of traffic volume will be provided by private car.

We assume that with the fuel efficiency improvement, $\mathrm{CO}$ emission of private car will reduce by $40 \%, \mathrm{NO}_{x}$ emission reduce by $56 \%$ and $\mathrm{CO}_{2}$ emission reduce by $25 \%$. The substitution of gasoline with liquefied petroleum gas (LPG) will reduce $\mathrm{CO}$ emission by $75 \%, \mathrm{NO}_{x}$ emission by $40 \%$ and $\mathrm{CO}_{2}$ emission by $25 \%$ [28]. Although the alternative fuels are perceived as one of the most important solutions to Beijing's environmental problems, considering the scale and cost of the infrastructure development, we assume that only $25 \%$ of private car and $90 \%$ of bus will use LPG fuels in 2020 .

\subsubsection{Results of scenario analysis}

The environmental impacts of the scenarios are shown in Table 5. To provide one passenger-km service, the low motorization level scenario's CO emission is $8.96 \mathrm{~g}$, which is 1.18 times higher than base year; the middle motorization level scenario's $\mathrm{CO}$ emission is $17.89 \mathrm{~g}$, which is 2.36 times higher 
Table 5

Environmental impacts of different scenarios (g/passenger-km)

\begin{tabular}{|c|c|c|c|c|c|c|c|c|c|c|c|c|}
\hline & \multicolumn{3}{|c|}{ Beijing 2000} & \multicolumn{3}{|l|}{ BAU } & \multicolumn{3}{|c|}{ Fuel efficiency improvement } & \multicolumn{3}{|c|}{ Fuel substitute } \\
\hline & $\mathrm{CO}$ & $\mathrm{CO}_{2}$ & $\mathrm{NO}_{x}$ & $\mathrm{CO}$ & $\mathrm{CO}_{2}$ & $\mathrm{NO}_{x}$ & $\mathrm{CO}$ & $\mathrm{CO}_{2}$ & $\mathrm{NO}_{x}$ & $\mathrm{CO}$ & $\mathrm{CO}_{2}$ & $\mathrm{NO}_{x}$ \\
\hline Base year & 7.59 & 19.03 & 0.40 & & & & & & & & & \\
\hline Middle motorization level & & & & 17.89 & 42.64 & 0.83 & 11.03 & 32.75 & 0.44 & 9.88 & 32.05 & 0.34 \\
\hline High motorization level & & & & 28.60 & 66.09 & 1.19 & 17.18 & 49.64 & 0.53 & 16.07 & 49.58 & 0.47 \\
\hline
\end{tabular}

than the base year; and the high motorization level scenario's $\mathrm{CO}$ emission is 3.77 times more than base year. The fuel efficiency improvement and fuel substitution have a large potential in mitigating the environmental emissions compared to BAU. In low motorization level scenario, if fuel efficiencies are improved and fuel substation measures are taken, then the $\mathrm{CO}, \mathrm{CO}_{2}$ and $\mathrm{NO}_{x}$ emission level will be reduced by $38 \%, 17 \%$ and $22 \%$, respectively. Nevertheless, in high motorization level scenario, even these measures are taken, the air emissions still maintain a high level compared with base year. This reflects the important role of consumers' behavior.

\section{Conclusions and policy implications}

\subsection{Conclusions from the scenario analysis}

The scenario results reflect the combining role of consumers and producers. The low motorization level of private traffic mode, to a certain extent, is a kind of sustainable consumption behavior. The realization of fuel efficiency improvement and fuel substitute depends on the technological development of producers, and the sustainable vehicles they provide. From the results of scenario analyses, we can find that the lowest air emissions appear in low motorization level scenario, if technological improvements were made. We can conclude that both sustainable consumption and production are necessary for a sustainable private pattern, based on our scenario analysis.

What kind of private pattern consumers choose and what kind of technology producers use are greatly influenced and directed by the government [18], especially in China's command-and-control management systems. To promote economic development and increase living standards, the Beijing Municipal government, which views private car fleet level as an important sign of its achievement, took a series of measures to stimulate private car development. Although strict emission standards are taken, the shortage of land and severe air pollution status prohibit Beijing from following the high motorization model. It is becoming increasingly clear that advances in technology will not be necessarily sufficient to overcome increasing environmental impacts from a growing motor vehicle fleet, desire for larger cars and increasing vehicle-miles travel. Concerning the status of Beijing, we conclude the government should pay more attention to consumption while they promote technological innovation.

\subsection{Policy implications}

From the consumption point of view, traffic is a demand necessary to meet the movement requirements of people. The environmental problem of traffic is not caused by the demand itself, but by the modes that people choose to meet the demand. In this sense, to realize sustainable private traffic consumption, the government on one hand should encourage people to choose an environmentally friendly traffic mode, and to offer less environmentally harmful mobility services on the other.

Behavioral change not only influences what transport modes are chosen, but also the usage efficiency, such as traffic flow, driving modes and occupancy rates. The government may take some measures and instruments to influence people's traffic behaviors. One of the effective ways is to internalize the external social and environmental costs of private cars. These policies include stringent and expensive driver licensing and vehicle taxes, establishment of car-free zones in dense areas, promulgation of rules on the formation and operation of auto companies.

Car-sharing is another innovative option for Beijing. The shared-use vehicle systems can improve transportation efficiency by reducing the number of private vehicles required to meet travel demand. The traditional complex living style makes private car useful only for holidays or tourism, such non-recurrent trips can be easily accomplished with shared vehicles [29]. The rapidly developing new towns in Beijing should offer this car-sharing system.

Technological development will still play an important role in emissions reduction and vehicle energy efficiency improvement. The government should make good use of new technological innovations, and take advantage of being able to select from the latest technology policies of developed countries. Economic incentive mechanisms should be designed to encourage investment, research and technology development, and provide the consumers with more choices of environmental friendly vehicles.

At the same time, the government should try to offer attractive transportation alternatives. Public transit including bus, minibus and rail metro system should be the important alternatives to private cars. The government should ensure that meeting traffic demands will be equally convenient to those with and without a car.

In the end, we call for the government and scientists to identify specific activities, tools, policies, and measures to monitor and assess dynamic and mechanisms of consumption 
behavior, and establish consumer-oriented policies, which at a short-term could reduce employment of private cars and in the long-term could change social behavior patterns.

\section{Acknowledgments}

This research was supported by the National Basic Research Program of China (2005CB724206) and the Chinese National Scientific Foundation (No. 70433001). We gratefully acknowledge the discussions with and the support of Juergen Paulussen and other colleagues.

\section{References}

[1] United Nations. World summit on sustainable development: plan of implementation. New York: United Nations; 2002.

[2] United Nations Environment Programme. Proposal for a work programme on promoting sustainable consumption and production patterns. Paris; 2002.

[3] Barber J. Production, consumption and the world summit for sustainable development. Rockville, MD: Integrative Strategies Forum; 2003.

[4] State Environmental Protection Administration of China. China's agenda 21: white paper on China's population, environment, and development in the 21st century. Beijing: Chinese Environmental Sciences Publisher; 1994.

[5] United Nations Environment Programme. Sustainable consumption a global status report. Paris; 2002.

[6] Geyer-Allely E, Zacarias-Farah A. Policies and instruments for promoting sustainable household consumption. J Clean Prod 2003;11:923-6.

[7] Shrestha RM, Anandarajah G, Adhikari S, Jiang KJ, Zhu SL. Energy and environmental implications of $\mathrm{NO}_{x}$ emission reduction from the transport sector of Beijing: a least-cost planning analysis. Transport Res Part D 2005; 10:1-11.

[8] Zhu S, Jiang K. Analyses of technical options for mitigating $\mathrm{CO}_{2}$ emission from an urban transport system: a case study of Beijing city. Int $\mathrm{J}$ Environ Pollut 2003;19:483-97.

[9] Energy Information Administration. International energy outlook. Washington, DC: U.S. Department of Energy; 2000.

[10] Beijing Municipal Bureau of Statistics. Beijing statistical yearbook 2002. Beijing: China Statistics Press; 2002.

[11] Beijing Municipal Bureau of Statistics. Beijing statistical yearbook 2004. Beijing: China Statistics Press; 2004.
[12] Zhu JG, Li W. Analyzing of the issues and polices of Beijing Traffic. Proceedings of annual scientific committee of China's urban transportation planning. Beijing; 2003.

[13] Fu LX, Hao JM, He DQ, He KB. The emission characteristics of pollutants form motor vehicles in Beijing. Environ Sci 2000;21(3): $68-70$.

[14] Hao JM, Wu Y, Fu LX, He KB, He DQ. Motor vehicle source contributions to air pollutants in Beijing. Environ Sci 2001;22(5):1-6.

[15] Organization for Economic Co-operation and Development. Report on the OECD policy meeting on sustainable consumption and individual travel behaviour. Paris: Organization for Economic Co-operation and Development; 1997.

[16] Schafer A, Victor DG. The future mobility of the world population. Transport Res Part A 2000;34:171-205.

[17] Chinese Academy of Engineering, National Academy of Engineering, National Research Council. Personal cars and China. Beijing: China Machines Press; 2003.

[18] Wu CS. Research of urban transportation in China. Beijing: China Science and Technology Press; 2000.

[19] Riley K. Motor vehicles in China: the impact of demographic and economic changes. Popul Environ 2002;23(5):479-94.

[20] World Executive Network. Top 25 popular cars in Ya Yun Cun cars market 2004, http://www.icxo.com; 2005.

[21] Beijing Municipal Government. Beijing master plan (2004-2020). Beijing: Beijing Municipal Government; 2005.

[22] Gan L. Globalization of the automobile industry in China: dynamics and barriers in greening of the road transpiration. Energy Policy 2003;31: 537-51.

[23] Yin YG, Wang M. China's urban environmental sustainability in a global context. In: Low N, editor. Consuming cities: the urban environment in the global economy after the Rio declaration. New York: Routledge; 2000.

[24] Ropke I. The environmental impact of changing consumption patterns: a survey. Int J Environ Pollut 2001;15(2):127-45.

[25] Garvin L, Henry N, Vernon M. Community materials flow analysis: a case study of Ann Arbor. Ann Arbor: University of Michigan; 2000.

[26] Yang JX, Nielsen PH. Chinese life cycle impact assessment factors. J Environ Sci 2001;13(2):205-9.

[27] Zhu SL, Jiang KX. Forecast of Beijing urban transport energy consumption and pollution. China Energy 2002;6:26-31.

[28] Zhang JT, Liang SR, Ding LQ. Clean alternative fuels for vehicle engines and development prospect. Adv Fine Petrochemicals 2005;6(4): 43-7.

[29] Barth M, Shaheen SA. The potential for shared-use vehicle system in China. Davis, California: University of California; 2003. 